\title{
Calculated Accessibilities and Nucleophilicities of Linear and Cyclic Amines for Carbon Dioxide Absorption Reactions
}

\author{
Jae-Goo Shim, Young H. Jhon, ${ }^{\dagger, *}$ Jun-Han Kim, Ji Hyun Lee, In-Young Lee, Kyung-Ryong Jang, and Jaheon Kim ${ }^{\dagger, *}$ \\ Global Environment Research Group, Environment \& Structure Laboratory, Korea Electric Power Research Institute, \\ Daejeon 305-380,Korea. E-mail: youngjhon@gmail.com,jaheon@ssu.ac.kr \\ †Department of Chemistry, Soongsil University, Seoul 156-743, Korea \\ Received March 24, 2011, Accepted July 4, 2011
}

Key Words : $\mathrm{CO}_{2}$, Cyclic, Linear, Amines, Accessibility, MD, Nucleophilicity, DFT

$\mathrm{CO}_{2}$ capture by aqueous amines is an important technology that is readily applicable to current coal-fired power plants. ${ }^{1}$ It involves $\mathrm{CO}_{2}$ in flue gases reacting with aqueous amines to form water-soluble carbamate before the gases' emission to the atmosphere (eq. 1). The captured $\mathrm{CO}_{2}$ is then released and separated by scrubbing which also regenerates the amine for reuse. For example, monoethanolamine (MEA), a representative $\mathrm{CO}_{2}$-absorbent, quickly absorbs $\mathrm{CO}_{2}$ at $c a .40^{\circ} \mathrm{C}$, and its carbamate can dissociate into $\mathrm{CO}_{2}$ and MEA at $c a .120^{\circ} \mathrm{C}{ }^{2}$

$$
\begin{gathered}
\mathrm{RNH}_{2}+\mathrm{CO}_{2}+\mathrm{B} \rightarrow \mathrm{RNHCOO}+\mathrm{BH}^{+} \\
\left(\mathrm{R}=\mathrm{HO}\left(\mathrm{CH}_{2}\right)_{2}\left(\mathrm{CH}_{2}\right)_{2}-\mathrm{B}=\text { base }\right)
\end{gathered}
$$

For improved economy, other amines such as KS-1 are under development. ${ }^{3}$ Much research is underway to find or synthesize efficient amines with faster absorption kinetics, higher $\mathrm{CO}_{2}$ capacities, and lower regeneration temperatures than MEA. ${ }^{4}$

Besides experimental work, quantum mechanical computations of $\mathrm{CO}_{2}$-absorption have been conducted, although they mainly focus on understanding reaction mechanisms. ${ }^{5-8}$ Since these calculations are computationally expensive and can handle only small numbers of amines, simplified methods have been applied to predicting amines' reactivity through comparisons of the energy differences between amines' HOMOs and the LUMO of $\mathrm{CO}_{2} \cdot{ }^{9,10}$ This approach is, however, not sufficient for the full evaluation of amines' performance. A new approach for the quantitative estimation of amines' reactivity has been proposed that considers both the dynamic accessibility and nucleophilicity of amines. ${ }^{10}$ Density functional theory (DFT) calculations of nucleophilicity do not consider steric hindrance around the nitrogen atoms in amines. Consideration of accessibility is required to estimate the reactivity of amines better. It can be included by counting the number of collisions between reactive centers ( $\mathrm{N}$ in amine, and $\mathrm{C}$ in $\mathrm{CO}_{2}$ ) during molecular dynamics (MD) simulations. This same approach was applied in this work for assessing the reactivities of cyclic and linear amines.

Cyclic amines such as piperazine, piperidine, and morpholine are reported to react more quickly with $\mathrm{CO}_{2}$ than linear amines such as MEA, and DEA (diethanolamine). ${ }^{11-15}$ However, this observation is simply correlated to the amines'

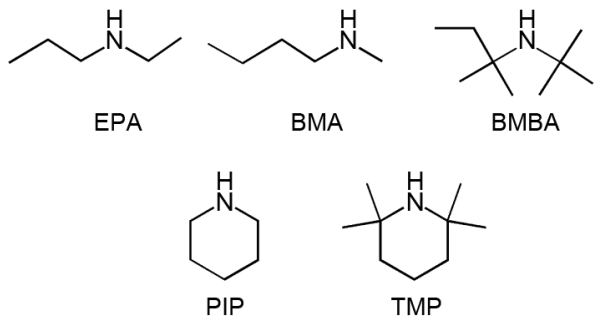

Scheme 1. The amines studied herein: EPA $\left(\mathrm{C}_{5} \mathrm{H}_{13} \mathrm{~N}\right.$, ethylpropylamine), BMA $\left(\mathrm{C}_{5} \mathrm{H}_{13} \mathrm{~N}, N\right.$-butylmethyl amine $)$, BMBA $\left(\mathrm{C}_{9} \mathrm{H}_{21} \mathrm{~N}\right.$, $N$-tert-buthyl-2-methylbutane-2-amine), PIP $\left(\mathrm{C}_{5} \mathrm{H}_{11} \mathrm{~N}\right.$, piperidine), and TMP $\left(\mathrm{C}_{9} \mathrm{H}_{19} \mathrm{~N}, 2,2,6,6\right.$-tetramethyl piperidine $)$.

basicity; more basic amines, as better Lewis bases, would react more favorably with $\mathrm{CO}_{2}$, a Lewis acid. To assess reactivity quantitatively, two cyclic and three linear secondary amines were selected as model compounds (Scheme 1), and their electronic reactivities and accessibilities were investigated. BMBA and TMP are considered to be sterically hindered (abv. hindered). ${ }^{16}$ Hindered amines generally absorb $\mathrm{CO}_{2}$ more slowly than unhindered amines, and their carbamates are unstable in aqueous solution. ${ }^{16 \mathrm{~b}}$

Global Nucleophilicity. All primary and secondary amines can act as nucleophiles toward electrophilic $\mathrm{CO}_{2}$. Before calculating the nucleophiles' global nucleophilicity indices, $\omega^{-}$, the amines' structures were optimized and the energies of the final structures were calculated by DFT (Figure 1). Table 1 lists the global nucleophilicities of the amines in this work (See also Supporting Information). For comparison, the nucleophilicities of reference amines MEA, MAE (2-methylamino-ethanol), and a representative hindered amine, AMP (2-amino-2-methyl-1-propanol) are included. ${ }^{10}$ These amines have additional - $\mathrm{OH}$ groups that can form hydrogen bonds with the amine groups, and are smaller molecules than the compounds in Scheme 1.

Global nucleophilicities in Table 1 are enhanced in species with electron donating methyl groups bonded to $\mathrm{N}$ atoms: $($ BMBA, TMP) $>$ others; MAE > (AMP, MEA). In addition, the secondary amines with more carbon atoms are more nucleohpilic than the smaller amines: (BMBA, TMP, PIP, EPA, BMA) > (MAE, AMP, MEA). However, nucleophilicity 
(a)

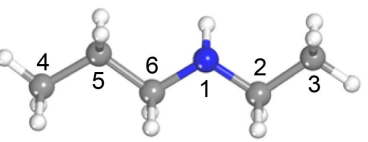

(b)

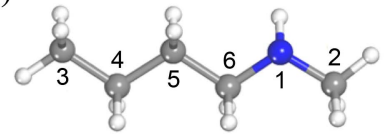

(c)

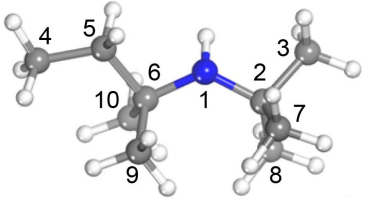

(d)

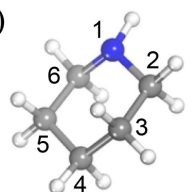

(e)

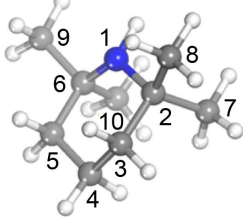

Figure 1. DFT-optimized molecular structures with atomic numberings: (a) EPA, (b) BMA, (c) BMBA, (d) PIP, and (e) TMP.

Table 1. Global nucleophilicities (w) of the amines in this work

\begin{tabular}{ccccc}
\hline Compound & IP $(\mathrm{eV})$ & EA $(\mathrm{eV})$ & $\omega^{-}$ & $\begin{array}{c}p K_{\mathrm{a}}^{18} \\
\left(25^{\circ} \mathrm{C}, \text { in water }\right)\end{array}$ \\
\hline EPA & 5.622 & 0.692 & 0.1411 & - \\
BMA & 5.614 & 0.695 & 0.1412 & - \\
BMBA & 5.468 & 0.703 & 0.1461 & - \\
PIP & 5.584 & 0.712 & 0.1414 & 11.123 \\
TMP & 5.479 & 0.749 & 0.1433 & - \\
MEA & 6.103 & 0.953 & 0.1115 & 9.5 \\
MAE & 5.703 & 0.943 & 0.1256 & 9.88 \\
AMP & 5.779 & 0.954 & 0.1225 & 9.694 \\
\hline
\end{tabular}

cannot predicit reactivity exactly because of the effects of hindrance, with BMBA and TMP having much lower rates of $\mathrm{CO}_{2}$ absorption. Large nucleohpilicity is not always correlated lineraly with fast reaction. For example, AMP is more nucleophilic than MEA, but its $\mathrm{CO}_{2}$ absorption rate constant is much smaller. ${ }^{17}$ Reactivity is linked to nucleophilicity among similar amines, such as the non-hindered amines, of which PIPis the most reactive: PIP > (EPA, BMA, MAE, MEA). ${ }^{12,13}$

Nucleophilicity can be further analyzed by calculating atomic nucleophilicity by Fukui functions (Table 2, see also Computational Methods). The charge densities of $\mathrm{N}$ atoms in TMP and BMBA were found to be $-0.727 \mathrm{e}$ and $-0.730 \mathrm{e}$, respectively, and in the unfunctionalized amines PIP, EPA, and BMA, $-0.711 \mathrm{e},-0.703 \mathrm{e}$, and $-0.701 \mathrm{e}$, respectively. This indicates that the nitrogen atoms of TMP and BMBA are subject to induction by the electron donating methyl groups; the net charges of four methyl groups in TMP and BMBA are $+0.078 \mathrm{e}$ and $+0.066 \mathrm{e}$, respectivley. However, all the linear amines (BMBA, EPA, BMA) showed larger atomic nucleophilcities ( $c a .0 .53)$ than the cyclic amines, TMP, PIP (ca. 0.51), which is uncorrelated with the trend of global nucleophilicity. So, global nucleophilicity appears to be a better indicator of amines' reactivity than atomic nucleophilicity. ${ }^{10}$ Unfortunately, these results do not explain why the electronic reactivity of the cyclic amine, PIP is greater
Table 2. Condensed Fukui functions $\left(f_{k}^{-}\right)$and NPA charges (e, in parentheses) of non-hydrogen atoms in five amines; values for hydrogen atoms are omitted for simplicity. $\mathrm{f}_{\mathrm{k}}{ }^{-}$with summation over $k$ normalized to unity is a measure of a molecule's relative nucleophilicity

\begin{tabular}{cccccc}
\hline Atom & EPA & BMA & BMBA & PIP & TMP \\
\hline \multirow{2}{*}{ N1 } & 0.536 & 0.537 & 0.530 & 0.513 & 0.515 \\
& $(-0.703)$ & $(-0.701)$ & $(-0.730)$ & $(-0.711)$ & $(-0.727)$ \\
C2 & -0.051 & -0.044 & -0.019 & -0.036 & -0.014 \\
& $(-0.173)$ & $(-0.362)$ & $(0.120)$ & $(-0.178)$ & $(0.124)$ \\
C3 & -0.007 & 0.002 & -0.017 & 0.032 & -0.010 \\
& $(-0.583)$ & $(-0.573)$ & $(-0.577)$ & $(-0.392)$ & $(-0.384)$ \\
C4 & -0.002 & -0.004 & 0.003 & -0.022 & -0.006 \\
& $(-0.576)$ & $(-0.380)$ & $(-0.582)$ & $(-0.386)$ & $(-0.386)$ \\
C5 & 0.028 & 0.032 & 0.000 & 0.032 & -0.010 \\
& $(-0.389)$ & $(-0.386)$ & $(-0.378)$ & $(-0.392)$ & $(-0.384)$ \\
C6 & -0.047 & -0.044 & -0.016 & -0.036 & -0.014 \\
& $(-0.169)$ & $(-0.168)$ & $(0.129)$ & $(-0.178)$ & $(0.124)$ \\
C7 & - & - & 0.001 & - & 0.032 \\
& & & $(-0.579)$ & - & $(-0.593)$ \\
C8 & - & - & 0.023 & - & -0.006 \\
& & & $(-0.595)$ & - & $(-0.571)$ \\
C9 & - & - & -0.014 & - & -0.006 \\
& & & $(-0.588)$ & $-0.571)$ \\
C10 & - & - & 0.028 & - & 0.032 \\
& & & $(-0.595)$ & & $(-0.593)$ \\
\hline
\end{tabular}

than those of the linear amines, EPA and BMA.

MD Simulations. A simple method of describing the degree of accessibility of a reactive site, e.g. $\mathrm{N}$ in amines, is to enumerate the exposed van der Waals surface of the site atoms. ${ }^{19}$ However, this does not consider important features of $\mathrm{CO}_{2}$ absorption: the orientation and the path of the incoming $\mathrm{CO}_{2}$ towards the lone pair of $\mathrm{N}$, and water molecules intervening between the reactants. It is noticeable that although the lone pair cannot be considered in the simulations, its position shall coincide with the $\mathrm{CO}_{2}$-accessible direction. Since this requires simulation in explicit solvent

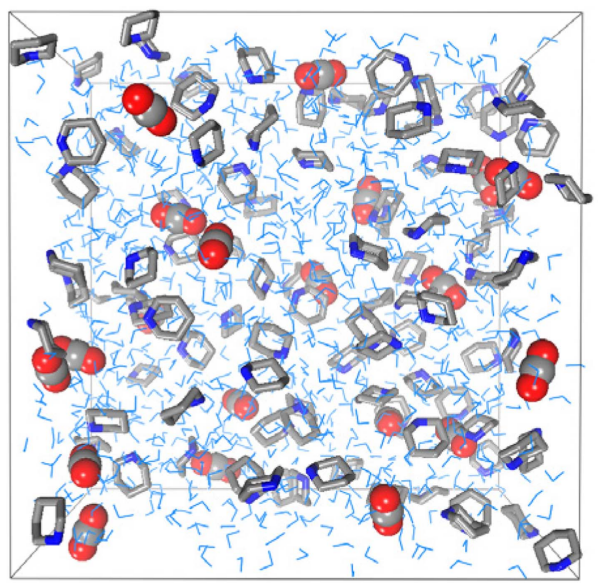

Figure 2. The commencement of an MD simulation of PIP. PIP and $\mathrm{CO}_{2}$ are depicted as sticks and CPK models, respectively. Water is shown as blue lines for simplicity. The hydrogen atoms in PIP are omitted for clarity. 
Table 3. Average accessibilities with standard deviations

\begin{tabular}{cccccccc}
\hline EPA & BMA & BMBA & PIP & TMP & MEA & MAE & AMP \\
\hline $988 \pm 117$ & $783 \pm 109$ & $286 \pm 78$ & $831 \pm 105$ & $501 \pm 105$ & $2413 \pm 195$ & $1160 \pm 159$ & $1712 \pm 154$ \\
\hline
\end{tabular}

environments, MD simulations were carried out in amine, $\mathrm{CO}_{2}$, and $\mathrm{H}_{2} \mathrm{O}$ systems (Figure 2), mimicking actual $\mathrm{CO}_{2}$ absorption. Accessibility was calculated by counting the number of van der Waals contacts between $\mathrm{CO}_{2}$ and amine molecules (Table 3). ${ }^{10}$

The accessibility data show that the smaller reference amines were more likely to contact $\mathrm{CO}_{2}$ than the larger amines: (MEA, AMP, MAE) > (EPA, PIP, BMA, TMP, BMBA). As expected, the non-hindered amines (MEA, MAE, EPA, PIP, BMA) were more accessible by $\mathrm{CO}_{2}$ than TMP and BMBA that have many groups around their $\mathrm{N}$ atoms. In general, accessibility is inversely proportional to nucleophilicity because the functional groups bonded to the $\mathrm{N}$ atoms of the larger amines contribute to increasing their nucleophilicity but sterically congest around the $\mathrm{N}$ atoms: accessibility, (EPA $>$ PIP $>$ BMA) $>$ (TMP $>$ BMBA) vs. nucleophilicity, $(\mathrm{BMBA}>\mathrm{TMP})>(\mathrm{PIP}>\mathrm{EPA} \sim \mathrm{BMA})$.

Since the cyclic amine lacks side chains that can reach the $\mathrm{N}$, PIP is expected to be more accessible than BMA. However, it is not obvious why EPA, with two flexible side chains, can access $\mathrm{CO}_{2}$ more easily than PIP. It is plausible that the direction of the nitrogen lone pair in PIP is almost fixed in the six-membered ring, decreasing the area accessible to $\mathrm{CO}_{2}$. In contrast, the alkyl groups bonded to nitrogen in EPA have a greater degree of rotational freedom, facilitating the nitrogen's lone pair to meet $\mathrm{CO}_{2}$. Similar is possible for BMA, but with an increased possibility of intervention by its longer alkyl chain $\left(\mathrm{H}_{3} \mathrm{C}-\mathrm{CH}_{2}-\mathrm{CH}_{2}-\mathrm{CH}_{2}-\right)$ than that $\left(\mathrm{H}_{3} \mathrm{C}-\mathrm{CH}_{2}-\mathrm{CH}_{2}-\right)$ of EPA. Otherwise, the compact structure of PIP appears advantageous in terms of accessibility than the flexible linear amines. It is interesting to note that the difference in accessibility between BMBA and EPA (-702) is larger than that of PIP and TMP (-330). Unlike EPA, the conformation of BMBA is very restricted due to its four methyl groups, its steric congestion is severe and highly unfavorable for accessing $\mathrm{CO}_{2}$.

Conclusions. The nucleophilicity and accessibility of two cyclic and three linear amines were invesetigated. Global nucleophilicity was ranked: BMBA $>$ TMP $>$ PIP $>$ EPA BMA $(>$ MAE $>$ AMP $>$ MEA), and accessibility was ranked: $(\mathrm{MEA}>\mathrm{AMP}>\mathrm{MAE}>$ ) $\mathrm{EPA}>\mathrm{PIP}>\mathrm{BMA}>$ TMP $>$ BMBA. The most nucleophilic amine, BMBA, had the lowest accessibility, and therefore, is unlikely to be efficient for the $\mathrm{CO}_{2}$ absorption. Likewise, cyclic and hindered TMP is not anticipated to be an efficient $\mathrm{CO}_{2}$ absorber. Like BMBA and TMP, amines can have high nucleophilicity, low accessibility (or vice versa), and difficult to predict reactivitiy. For example, MAE is more nucleophilic but less accessible to $\mathrm{CO}_{2}$ than either MEA or AMP; it was found to be msore reactive than MEA or AMP (Table 4).

Of the non-hindered amines, cyclic PIP is more nucleophilic (0.1414) than the linear amines, EPA (0.1411), and
Table 4. Second order rate constants of some amines

\begin{tabular}{ccccc}
\hline Compounds & MEA & MAE & AMP & PIP \\
\hline $2^{\text {nd }}$ order rate & $3.63^{17 \mathrm{a}}$ & $7.99^{17 \mathrm{a}}$ & $0.42^{17 \mathrm{a}}$ & \\
constant & $3.63^{17 \mathrm{~b}}$ & $7.94^{17 \mathrm{~b}}$ & $0.520^{17 \mathrm{~d}}$ & $60.2^{15}$ \\
$\left(\mathrm{~m}^{3} \mathrm{~mol}^{-1} \mathrm{~s}^{-1}\right)$ at & $4.09^{17 \mathrm{c}}$ & $5.01^{17 \mathrm{c}}$ & $1.185^{17 \mathrm{e}}$ & \\
$298 \mathrm{~K}$ & $5.545^{17 \mathrm{~d}}$ & & & \\
\hline
\end{tabular}

BMA (0.1412). However, its accessibility (831) was found to be between those of EPA (988) and BMA (783). As experimental data are available only for PIP, indirect analysis is required for comparison with MAE. While PIP is more nucleophilic (0.1414) than MAE (0.1256), and less accessible (831 compared with 1160), its rate constant is greater than that of MAE (Table 4). This implies that improved nucleophilicity can overcome low accessibility if an amine's $\mathrm{N}$ atoms are not heavily blocked by neighboring functional groups. ${ }^{10}$ Therefore, it is expected that PIP will react with $\mathrm{CO}_{2}$ more quickly than EPA and BMA.

While cyclic amines' reactivities have been previously predicted only by their $\mathrm{p} K_{\mathrm{a}}{ }^{11,12}$ the approach reported herein is more reliable because it considers both the elctronic and structural properties. However, combining nucelophicity and accessibility into a united parameter remains to be done. This requires further collection of theoretical data, and careful analysis of their correlation with referrance to experimental data.

\section{Computational Methods}

DFT Calculations. All DFT calculations ${ }^{20}$ were carried out using the Gaussian 03 suite of programs. ${ }^{21}$ Geometry optimization and energy calculations for the compounds and their reduced or oxidized states were performed on the computational level of DFT with the B3LYP functional. ${ }^{20}$ For the energy calculation, we used an aqueous solvation model, PCM (Polarizable Continuum Model) developed by Tomasi et al. ${ }^{22}$ The adopted basis set was $6-311++\mathrm{G}(\mathrm{d}, \mathrm{p})$, and the cavities of the solvation model were given using the UFF radii. ${ }^{23}$

Molecular Dynamics Simulations. MD simulations were performed with the NVT ensemble using the Tinker molecular modeling package ${ }^{24}$; $\mathrm{we}^{10}$ and others ${ }^{25}$ employed NVT ensembles for the simulations on amine- $\mathrm{CO}_{2}$ absorption reactions. Berendsen temperature control was used with a decay constant of $\tau=0.1 \mathrm{ps}$ and a time step of $1 \mathrm{fs}$. Operation temperature was set at $40{ }^{\circ} \mathrm{C}$, that of industrial $\mathrm{CO}_{2}$ absorption units that employ amines. An OPLS (Optimized Potential for Liquid Simulations) all-atom forcefield was adopted. ${ }^{26}$ The forcefield parameters specific to this system were obtained from the literature..$^{27}$ A cutoff radius of $9 \AA$ was used for the computaitons of both electrostatic and van der 
Waals forces. Due to the large number of atoms, the Ewald summation was not applied to save computation time. The system was composed of amine, $\mathrm{CO}_{2}$, and $\mathrm{H}_{2} \mathrm{O}$ molecules. For the cyclic amines, $1000 \mathrm{H}_{2} \mathrm{O}, 100 \mathrm{PIP}$ (or TMP), and 20 $\mathrm{CO}_{2}$ molecules were enclosed in a cube of length 36.29 (or 39.03) $\AA$. The composition corresponded to $\sim 32.1$ or $\sim 43.9$ wt \% PIP or TMP aqueous solution. Systems for the linear amines (EPA, BMA and BMBA) were constructed to have the same molar concentrations as the cylcic amine systems. i.e., systems included 100 amine molecules, $20 \mathrm{CO}_{2}$ molecules and, for EPA: $901 \mathrm{H}_{2} \mathrm{O}$ molecules; for BMA: $891 \mathrm{H}_{2} \mathrm{O}$ molecules; and for BMBA: $894 \mathrm{H}_{2} \mathrm{O}$ molecules. For each amine system, nine configurations were used with random spatial distributions of the reactants. The MEA system contained $1000 \mathrm{H}_{2} \mathrm{O}, 100 \mathrm{MEA}$, and $20 \mathrm{CO}_{2}$ molecules. The systems for AMP and MAE were built maintaining same molar concentrations. Geometric enegy-minimization of the systems were carried out prior to MD computation. Each MD simulation was performed for 120 ps, with 20 ps equilibration and 100 ps production phases; we have compared the pair correlation function, $\mathrm{g}(\mathrm{r})$ for BMBA to support that the system has approached equilibrium until 20 ps (See Supporting Information). Two thousand samples of the $x y z$ coordinates were recorded at $50 \mathrm{fs}$ intervals and analyzed using a program coded in the laboratory. When an $\mathrm{N}$ atom in the amine and a $\mathrm{C}$ atom in $\mathrm{CO}_{2}$ were in van der Waals contact, it was considered a collision and access was counted. For each amine, nine sets of MD simulations were conducted, and the average number of contacts was considered its accessibility. During the simulations, access numbers were counted from the analyses of the sampled trajectories.

Acknowledgments. This work was supported by the Power Generation \& Electricity Delivery grant (2010201020006A) of the Korea Institute of Energy Technology Evaluation and the Planning (KETEP) grant funded by the Ministry of Knowledge Economy, Republic of Korea.

Supporting Information. The definitions of global and atomic nucleophilicities, and the pair correlation functions for BMBA are presented, which is available via the Internet, http://newjournal. kcsnet.or.kr.

\section{References}

1. Rao, A. B.; Rubin, E. S. Ind. Eng. Chem. Res. 2006, 45, 2421.

2. Kim, I.; Svendsen, H. F. Ind. Eng. Chem. Res. 2007, 46, 5803.

3. Zeman, F. Environ. Sci. Technol. 2007, 41, 7558.

4. (a) Bonenfant, D.; Mineault, M.; Hausler, R. Ind. Eng. Chem. Res. 2003, 42, 3179. (b) Bonenfant, D.; Mineault, M.; Hausler, R. Ind.
Eng. Chem. Res. 2005, 44, 3720. (c) Filburn, T.; Helble, J. J.; Weiss, R. A. Ind. Eng. Chem. Res. 2005, 44, 1542. (d) Filippis, R. D.; Giavarini, C.; Maggi, C.; Rinaldi, G.; Silla, R. Ind. Eng. Chem. Res. 2000, 39, 1364.

5. da Silva, E. F.; Svendsen, H. F. Int. J. Greenh. Gas. Con. 2007, 1, 151.

6. Arstad, B.; Blom, R.; Swang, O. J. Phys. Chem. A 2007, 111, 1222.

7. Xie, H.; Zhou, Y.; Zhang, Y.; Johnson, J. K. J. Phys. Chem. A 2010, 114, 11844

8. Shim, J. G.; Kim, J.-H.; Jhon, Y. H.; Kim, J.; Cho, K.-H. Ind. Eng. Chem. Res. 2009, 48, 2172.

9. (a) Chakraborty, A. K.; Bischoff, K. B.; Astarita, G.; Damewood, J. R., Jr. J. Am. Chem. Soc. 1988, 110, 6947. (b) Suda, T.; Zhang, Y.; Iwaki, T.; Nomura, M. Chem. Lett. 1998, 27, 189.

10. Jhon, Y. H.; Shim J.-G.; Kim J.; Lee, J. H.; Jang, K.-R.; Kim, J. J. Phys. Chem. A 2010, 114, 12907.

11. Bishnoi, S.; Rochelle, G. T. Chem. Eng. Sci. 2000, 55, 5531.

12. Cullinane, J. T.; Rochelle, G. Ind. Eng. Chem. Res. 2006, 45, 2531.

13. Derks, P. W. J.; Kleingeld, T.; Aken, C. V.; Hogendoorn, J. A.; Versteeg, G. F. Chem. Eng. Sci. 2006, 61, 6837.

14. Samanta, A.; Bandyopadhyay, S. S. Chem. Eng. Sci. 2007, 62, 7312.

15. Sharma, M. M. Trans. Faraday Soc. 1965, 61(508P), 681.

16. (a) Sartori, G.; Savage, D. W. Ind. Eng. Chem. Fundam. 1983, 22, 239. (b) Jo, E.; Jhon, Y. H.; Choi, S.; Shim, J.-G.; Kim, J.-H.; Lee, J. H.; Lee, I.-Y.; Jang, K.-R.; Kim, J. Chem. Commun. 2010, 46, 9158.

17. (a) Mimura, T.; Kumazawa, H.; Yagi, Y.; Takashina, T.; Yoshiyama, R.; Honda, A. Kagaku. Kogaku. Ronbun. 2006, 32, 236. (b) Ali, S. H.; Merchant, S. Q.; Fahim, M. A. Sep. Purif. Tech. 2002, 27, 121. (c) Mimura, T.; Suda, T.; Iwaki, I.; Honda, A.; Kumazawa, H. Chem. Eng. Comm. 1998, 170, 245. (d) Alper, E. Ind. Eng. Chem. Res. 1990, 29, 1725. (e) Sun, W.-C.; Yong, C.-B.; Li, M.-H. Chem. Eng. Sci. 2005, 60, 503.

18. Dean, J. A. Lange's Handbook of Chemistry; McGraw-Hill Inc.: fifteenth Ed., 1999.

19. (a) Lee, B.; Richards, M. J. Mol. Biol. 1971, 55, 379. (b) Fischer, B.; Holmes, B.; Miller, I. R.; Parsons, J. R.; Tung, L.; Hu, J. C.; Tsai, J. J. Struct. Biol. 2006, 153, 103.

20. Lee, C.; Yang, W.; Parr, R. G. Phys. Rev. B 1988, 37, 785.

21. Frisch, M. J. et al. Gaussian 03, Revision D.01: Gaussian, Inc., Wallingford CT, 2004.

22. Miertus, S.; Scrocco, E.; Tomasi, J. Chem. Phys. 1981, 55, 117.

23. Rappé, A. K.; Casewit, C. J.; Colwell, K. S.; Goddard III, W. A.; Skiff, W. M. J. Am. Chem. Soc. 1992, 114, 10024.

24. Ponder, J. W. TINKER, Version 4.2 ed.: Washington University: St. Louis, MO, 2004

25. Han, B.; Zhou, C.; Wu, J.; Tempel, D. J.; Cheng, H. J. Phys Chem. Lett. 2011, $2,522$.

26. Jorgensen, W. L.; Maxwell, D. S.; Tirado-Rives, J. J. Am. Chem. Soc. 1996, 118, 11225.

27. (a) Cadena, C.; Jennifer, L; Anthony, L.; Shah, J. K.; Morrow, T. I.; Brennecke, J. F.; Maginn, E. J. J. Am. Chem. Soc. 2004, 126, 5300. (b) Yang, Q.; Xue, C.; Zhong, C.; Chen, J. AIChE J. 2007, 53, 2832. (c) Rizzo, R. C.; Jorgensen, W. L. J. Am. Chem. Soc. 1999, 121, 4827. (d) Damm, W.; Frontera, A.; Tirado-Rives, J.; Jorgensen, W. L. J. Comp. Chem. 1997, 18, 1955. (e) da Silva, E. F. Fluid. Phase. Equilib. 2004, 221, 15. 